\title{
Adaptação e aplicação de experimento de erosão do solo em Escola pública: reflexões didático-pedagógicas
}

\author{
AdAPTATION AND APPLICATION OF SOIL EROSION EXPERIMENT IN PUBLIC SCHOOL: DIDACTIC AND PEDAGOGICAL \\ REFLECTIONS \\ Letícia Severina de Quadros ${ }^{1}$, José Eduardo Sartori², Nádia Regina do Nascimento ${ }^{3}$ \\ 1- Licenciada e Bacharel em Geografia, pela UNESP, Rio Claro/SP. Profa. Secr. Educ. Est. São Paulo. leticia_unesp@yahoo.com.br \\ 2- Doutorando no Programa de Geociências e Meio Ambiente \\ Universidade Estadual Paulista "ú́lio de Mesquita Filho" Campus de Rio Claro/SP \\ sartori@rc.unesp.br \\ 3-Profa. IGCE/Depto. Planej. Territ. e Geoprocessamento, IGCE-UNESP, Rio Claro/SP. nascimr@rc.unesp.br
}

\begin{abstract}
The geoethics is an interdisciplinary field of ethics applied to geosciences, invoking an ethical and responsible attitude of humanity towards the geosphere. So the formation of environmental awareness and the dissemination of environmental education are essential, especially in young people. Thus, the school becomes the ideal stage to discuss and develop environmental education projects. This paper discusses the use of experimentation as a teaching tool. Furthermore, the adaptation of a portable soil erosion simulator is described, and the results of the application of a practical experiment in public school class are reported. The didactic approach adopted was to encourage active participation and the sharing of experiences of the students through interactive activities. Thus, it sought to improve perception, analytical skills, and exercise reflection and critical thinking of students by developing an emancipatory education. The preliminary and qualitative assessment of the activities showed a gain effective learning. Therefore, this work will contribute to the inclusion of the teaching of geosciences in schools.
\end{abstract}

\author{
Manuscrito: \\ Recebido: 29/2/2016 \\ Corrigido: $31 / 8 / 2016$ \\ Aceito: $21 / 10 / 2016$
}

Citation: Quadros L.S., Sartori J.E. , Nascimento N.R.2016.Adaptação e aplicação de experimento de erosão do solo em Escola pública: reflexões didático-pedagógicas. Terræ Didatica, 12(3):231-239. < http:// www.ige.unicamp.br/terraedidatica/ $>$.

Keywords: Experimentation; Soilerosion; Geoethics; Environmental education.

\section{Introdução}

As geociências têm como objetivo descrever e compreender os processos que regem a dinâmica do sistema Terra. Apesar disso, esta ciência geralmente é associada à destruição da natureza. Isto decorre do fato dos geólogos serem os responsáveis pela prospecção e pesquisa mineral. Assim, estes profissionais estão a serviço da mineração, que frequentemente gera grandes impactos ambientais negativos e, não raro, protagoniza casos de exploração e degradação humana.

O consumo de recursos naturais _renováveis e não-renováveis_tem crescido vertiginosamente devido ao desenvolvimento econômico e tecnológico advindo da revolução industrial. A despeito das profundas transformações na sociedade e da melhoria na qualidade de vida da população, a degradação ambiental chegou a níveis alarmantes e sem precedentes. A conscientização da população acerca deste problema decorrente da intensa atividade industrial, agropecuária, e extrativista ocorre paulatinamente. E a partir da segunda metade do século XX emerge o conceito de recurso ambiental, que engloba a capacidade da natureza fornecer recursos físicos necessários ao desenvolvimento econômico (recurso natural) e que agrega, também, o fato de a natureza desempenhar funções ecológicas essenciais de suporte à vida (Sánchez 2013).

$\mathrm{Na}$ década de 1990 surgiu a geoética, fundamentada no paradigma do desenvolvimento sustentável, segundo o qual "a satisfação das necessidades do presente não podem comprometer as das gerações vindouras" (Vasconcelos \& Almeida 2014), sendo preciso tomar atitudes concretas no sentido de uma justiça intra e intergeracional (Vasconcelos \& Imbernon 2015). A geoética é um campo interdisciplinar entre as geociências e a ética, centrada na 
reflexão crítica sobre o modo como a humanidade se relaciona com a geosfera, invocando uma atitude ética e responsável para com a geosfera.

Assim, é fundamental que se faça uma abordagem da natureza como meio de desenvolvimento da vida, mais do que simples fornecedora de materiais/ insumos necessários ao desenvolvimento econômico. Nada melhor do que a escola para discutir tais abordagens, usando como veículo principal a elaboração de projetos de educação ambiental.

O solo, como lugar da vida, é um tema de importância fundamental em estudos ambientais. Entretanto, este é pouco abordado no sistema de ensino brasileiro. Devido a sua grande complexidade e seu caráter interdisciplinar, o solo apresenta diferentes definições, que variam de acordo com a percepção de cada área do conhecimento. De maneira geral, o solo pode ser considerado como um meio contínuo composto por materiais minerais, orgânicos, líquidos - dentre os quais a água é o mais importante - e gases, e por seres vivos e em decomposição (Falconi \& Nascimento 2005). Ele apresenta diferentes funções como: suporte para plantas e organismos através de sustentação física, fornecimento de água e nutrientes; filtragem e armazenamento de água; fornecimento de materiais de construção; entre outras (Lepsch 2010). Além disso, é local de intensas trocas de energia e matéria, bem como ciclagem de nutrientes, sendo um importante elo de ligação ecossistêmico (Brady e Weil 2013).

No presente trabalho discute-se o uso da experimentação como ferramenta didática em educação ambiental e relata os resultados do projeto de extensão "Erosão de Solo: Pressupostos e Mecanismos - Produção de Material Paradidático" desenvolvido no Laboratório para Análises de Formações Superficiais (LAFS) da UNESP - campus de Rio Claro. Trata-se da adaptação de um experimento para demonstração de mecanismos de erosão do solo, que foi aplicado com sucesso em uma escola da Rede Pública de Ensino do Estado de São Paulo, no município de Rio Claro.

\section{Motivação e objetivos}

O presente trabalho tem por escopo analisar e avaliar qualitativamente o uso de um experimento portátil de erosão do solo como ferramenta didática em sala de aula. Além disso, busca-se subsidiar a inserção de tópicos relacionados às geociências, mais especificamente erosão dos solos no ensino médio. Para tanto, foram desenvolvidas atividades interativas e multissensoriais baseadas na geoética e no desenvolvimento sustentável.

A elaboração e execução da atividade se justificam pela escassez de experimentos voltados ao ensino fundamental e médio, tendo o solo como objeto de estudo. Tal fato torna o presente trabalho oportuno como procedimento didático de ensino, o qual entende-se que poderá ser uma contribuição efetiva para a Educação Ambiental nas Escolas.

\section{A experimentação no processo de aprendizagem}

A escola é o espaço para a experimentação e descobertas das potencialidades dos alunos. Dessa forma, tem-se um processo contínuo de aprendizagem tanto para o professor quanto para o aluno. Os materiais didáticos fazem parte da infraestrutura mínima para o ensino médio, de acordo com o Plano Nacional de Educação (PNE) de 2001 a 2010 (Brasil 2001a).

Na obra "Discurso do método", Descartes salienta que "as experiências são cada vez mais necessárias à medida que se avança no conhecimento". Vale (1998) salienta que a experimentação é uma alternativa para estimular a curiosidade e o espírito pesquisador do aluno. Para isso, o autor advoga por práticas experimentais a partir das quais o aluno pode observar a realidade concreta do mundo, como meio para se chegar ao processo de descoberta e de construção de relações significativas entre os fenômenos. Acredita-se que estimular a curiosidade e avançar o conhecimento são, também, virtudes da escola. As escolas podem oferecer um espaço maior para vivências de práticas didáticas experimentais e é onde se pode discutir, entender e compartilhar os resultados das descobertas e estabelecer as relações entre os fenômenos naturais entre si e com aqueles decorrentes da intervenção do homem, mas, sobretudo, permitir a busca de um sentido teórico para o que se quer introduzir a partir da experimentação. $\mathrm{O}$ entendimento do conteúdo teórico sobre um assunto pode ser facilitado, principalmente, quando este é acompanhado de um modelo prático e interativo. Assim, tem-se um intercâmbio de ideias, uma troca de experiências entre os próprios alunos e com o professor, que torna o conteúdo teórico mais acessível e simples, principalmente quando o conhecimento se torna presente no cotidiano do aluno, ampliando a sua percepção do mundo. 
Nessa perspectiva, as experiências, mutantes em decorrência do momento histórico, econômico e político que a sociedade passa ao longo do tempo, são necessárias, também, para o aumento da nossa percepção do mundo. Este é, portanto, o ponto de partida do trabalho que se apresenta.

A experimentação deve ser eficiente para levar o aluno a participar da sua própria aprendizagem. Imbernon et al. (2009) salienta que,

"A efetiva participação do aluno na obtenção do conhecimento é uma das chaves para que o aluno passe de seu comportamento de passividade à responsabilidade pelo seu próprio aprendizado".

Assim, a experimentação contribui de forma efetiva para o desenvolvimento social e cultural do aluno. Dessa forma, a experiência didática torna-se integradora durante o processo de ensino e aprendizagem, constituindo-se em uma ferramenta didático-pedagógica fundamental para abordar, investigar, discutir e transformar a educação de forma emancipatória. Desta maneira a atividade experimental deve estar fundamentada para ir além da observação, inserindo a teoria e a reflexão do indivíduo. Assim, tem-se a contribuição para a formação de cidadãos autônomos e conscientes, capazes de decidir e atuar na realidade socioambiental de modo comprometido com o bem-estar da sociedade.

A experimentação pode estar presente em diversos materiais, desde livros didáticos, guias para o professor, atividades de laboratório e documentários. Entretanto, o ensino de Geociências deve ter uma abordagem inovadora que represente a natureza, e que desenvolva métodos que despertem a atenção do aluno e o estimule a realizar novas descobertas. Em se tratando de uma proposta baseada na geoética a experimentação tem que permitir uma aprendizagem que promova a conexão entre o ser humano e o meio ambiente. O processo de construção do conhecimento pode ser estimulado, através de atividades interativas, com o compartilhamento de experiências culturais dos próprios alunos, o que lhes permite desenvolver novos conhecimentos e habilidades (Magagna et al. 2012). Então cabe ao professor, por outro lado, estimular o aluno a fazer questionamentos, elaborar perguntas, buscar evidências, e analisar os resultados das investigações.

A grande parte das escolas públicas do nosso país não possuem laboratórios didáticos, ou estes são subutilizados e isto constitui um problema para a efetivação da experimentação. Assim, torna-se necessário desenvolvermos metodologias e estratégias para aulas práticas com ênfase em trabalhos experimentais, buscando diferentes visões que contribuam para o processo de ensino-aprendizagem.

A presente pesquisa seguiu as indicações dos Parâmetros Curriculares Nacionais (PCNs). Os PCNs são diretrizes que têm como objetivo orientar e garantir o sistema educacional do País, nos seus níveis Fundamental e Médio (Brasil 2001b). Este documento é composto por uma coleção de volumes, organizados de forma a atender esses níveis de ensino, em todas as disciplinas dos currículos escolares. Sua função como instrumento pedagógico é auxiliar o professor na reflexão sobre seu trabalho (prática, projetos, análise de material didático), além de apontar caminhos que levem à busca de qualidade do sistema educacional, possibilitando ao aluno desenvolver-se como cidadão.

Os experimentos se inserem no terceiro e quarto ciclos do ensino fundamental, no conteúdo de Ciências Naturais. Para o ensino médio está dentro da temática Ciências da Natureza. Assim, o detalhamento da explicação dos fenômenos envolvidos no processo erosivo deve ser adequado ao nível dos alunos.

No ensino fundamental e médio o ensino de solos tem ênfase no seu caráter utilitário, com destaque para questões relacionadas à preservação e à conservação, em detrimento de uma abordagem mais conceitual de solo e de processos importantes, como a erosão (Falconi 2004). A carência de materiais didáticos e paradidáticos nesses níveis de ensino dentro da ciência do solo motiva o presente experimento.

\section{Algumas experiências de educação em ciência do solo}

Alguns projetos didáticos já foram desenvolvidos na Ciência do Solo, e mostraram a importância das diferentes abordagens dentro da sala de aula. Um dos trabalhos pioneiros é o projeto de extensão universitária "Solo na Escola", desenvolvido desde 2002 pelo Departamento de Solos e Engenharia Agrícola da Universidade Federal do Paraná (UFPR). Segundo Lima (2009), o projeto propiciou o desenvolvimento de atividades interativas com solos. Conta com um acervo de trinta e cinco experimentos. Estes últimos tratam de funções do solo que geralmente são negligenciadas no ensino fun- 
damental e médio, como: armazenamento de água da chuva, filtragem de impurezas das águas, suporte e reservatório de nutrientes para plantas, hábitat natural de organismos, e sequestro de carbono.

Falconi (2004) analisou a "Produção de material didático para o ensino de solos", e desenvolveu sua pesquisa salientando a importância da elaboração de novos materiais didáticos, a partir dos quais se pode chegar a alguns conceitos da ciência do solo. Como produto final a referida autora elaborou um kit de materiais didáticos contendo atividades práticas que podem ser usadas no processo de ensino e aprendizagem.

Já a Universidade de São Paulo, desde 2006 desenvolve o projeto de extensão universitária "ABC na Educação Científica - Mão na massa" dentro da Estação Ciência, na capital paulista. Este trabalho visa a capacitação de professores, sendo voltado para o ensino fundamental, em especial o primeiro ciclo (Falconi \& Athayde 2009).

Paralelamente a essas ações a EACH-USP, em parceria com a UNIFESP, mantém na rede um repositório de recursos voltados para a educação em ciências. Entre os materiais disponíveis há um módulo de experimentos com solos. As práticas utilizam uma abordagem simples e de fácil entendimento, procurando desenvolver o senso de observação das crianças. Os experimentos propostos têm caráter descritivo, com ênfase em aspectos como observação da paisagem, textura dos solos, pinturas, esculturas, influência da água no solo, e um simulador de erosão.

Em 2009 foi inaugurada a Estação Ciência do projeto de extensão universitária "Solo na Escola" (SNE) dentro da ESALQ-USP, inspirado no projeto homônimo da UFPR. A programação do SNE inclui visitas monitoradas, promoção de cursos e experimentoteca. Os experimentos também estão disponíveis na rede, e envolvem temas como composição, textura, e formação do solo, bem como erosão hídrica.

Outro projeto interessante foi desenvolvido em 2010 pelo Centro Nacional de Pesquisa de Milho e Sorgo da Embrapa. Trata-se da construção de um simulador de erosão para demonstrar o processo de erosão hídrica do solo. Assim, o experimento corresponde a uma ferramenta de educação ambiental, cujo objetivo era sensibilizar a população para o problema da perda de solo, buscando promover ações de conservação do solo (Miranda et al. 2010).

Por fim, pode-se citar o projeto Geoideias desenvolvido pelo Laboratório de Recursos Didá- ticos em Geociências, do Instituto de Geociências da Unicamp. O referido projeto corresponde a tradução e adaptação para a língua portuguesa dos experimentos da série Earth Learning Idea (Geologist's Association 2007). O objetivo desta série é desenvolver experimentos de baixo custo voltados para a educação básica dentro da temática das geociências. Os temas abordados são: a Terra como sistema, campo geomagnético, materiais terrestres, evolução da vida, tempo geológico, riscos naturais, recursos naturais e meio ambiente.

O presente trabalho corresponde a uma adaptação de um experimento de simulação de erosão do solo. Assim, buscou-se contribuir para a divulgação do ensino das geociências nas Escolas, e também auxiliar os professores na elaboração das aulas.

\section{Abordagem e fundamentação metodológica}

\section{Adaptação do experimento de erosão do solo}

$\mathrm{O}$ experimento utilizado no presente trabalho foi adaptado da montagem sobre erosão hídrica do projeto "Solo na Escola" da ESALQ-USP e do trabalho de Capeche (2009), utilizando os seguintes materiais: recipiente plástico transparente, rocha britada, amostra de solo contendo argila e areia, amostra de solo rica em matéria orgânica, gramíneas, regador, balde e jarra transparente com medidor. A escolha destes materiais se deu pela facilidade em encontrá-los no comércio, bem como ao seu baixo custo.

A base dos experimentos foi montada em uma bandeja plástica transparente de $45 \mathrm{~cm}$ de comprimento por $28 \mathrm{~cm}$ de largura $10 \mathrm{~cm}$ de altura (Fig. 1A). Este recipiente foi escolhido por ser leve, resistente, e possuir pegadores, facilitando o seu transporte e manuseio. Além disso, a transparência do recipiente permitiu a observação do perfil de solo pelos alunos, possibilitando verificar a dinâmica dos processos da erosão linear e laminar.

O perfil de solo construído (Figura 1) foi composto por três horizontes:

- Horizonte $\mathrm{C}$ - porção basal do perfil de solo, constituída por uma fina camada (aproximadamente dois centímetros) de pequenos fragmentos de rochas, representando o saprólito.

- Horizonte A - camada intermediária de quatro centímetros de espessura, composta por latossolo avermelhado com material mineral e matéria orgânica; 

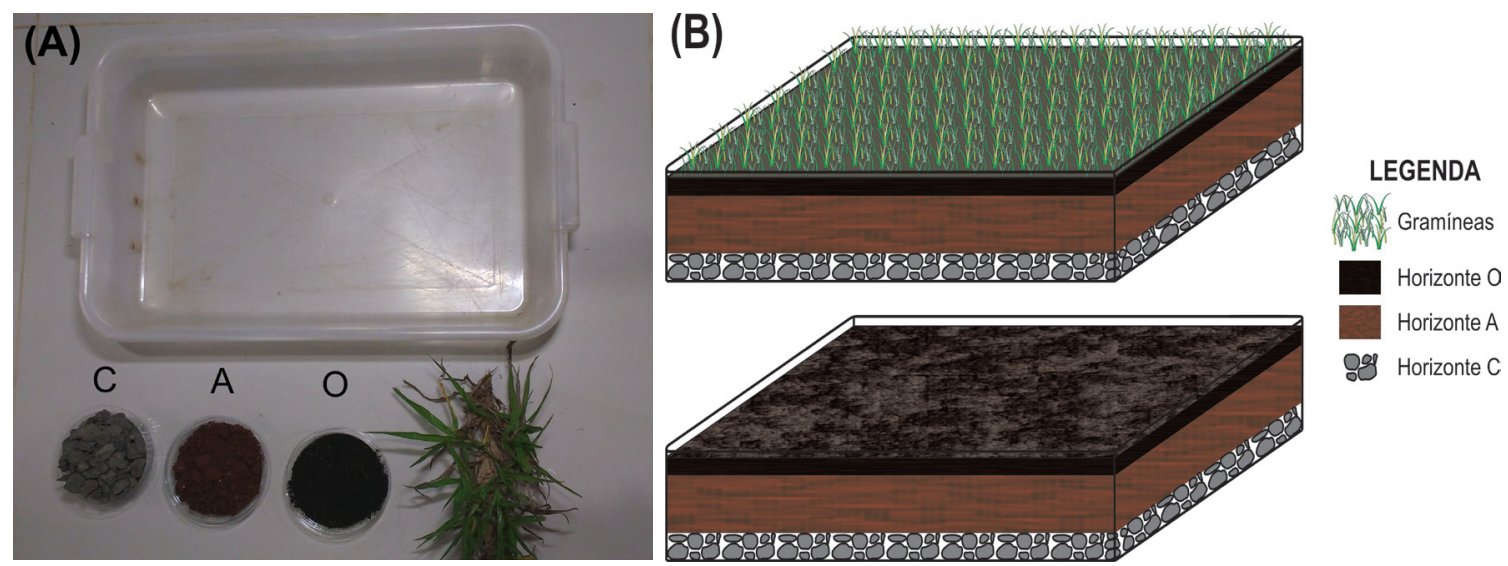

Figura 1. (A) Materiais utilizados para a confecção das montagens experimentais, indicando os horizontes de solo representados. (B) Representação esquemática mostrando os perfis de solo nas montagens com solo exposto e vegetado com gramíneas.

- Horizonte $\mathrm{O}$ - fina camada (dois centímetros de espessura) de topo, contendo matéria orgânica em decomposição;

A partir do perfil-base descrito foram realizadas duas montagens: um com solo exposto, e outro com cobertura vegetal de gramíneas (Figura 1B). Os modelos foram inclinados em aproximadamente $30^{\circ}$, através do uso de cunhas de madeiras. Em seguida, utilizou-se um regador cheio de água para simular uma chuva torrencial sobre o perfil de solo (Fig. 2). Desta maneira, foi possível simular os processos de erosão linear e laminar, respectivamente, na primeira e segunda montagens.

\section{Aplicação do experimento}

Os experimentos foram aplicados em uma turma composta por 35 alunos do $2^{\circ}$ ano do ensino médio na Escola Estadual Nelson Stroilli, no município de Rio Claro/SP. A escolha da escola se deve ao fato de sua localização, no Jardim Ipanema, onde se concentra uma grande comunidade carente na periferia da cidade. Além disso, o bairro não é atendido por projetos sociais ou de extensão de cunho educativo ou ambiental.

Durante a aula foi adotada uma abordagem/ postura de professor facilitador, procurando promover e estimular a participação dos alunos, bem como guiar e moderar o debate de ideias.

Iniciou-se o experimento em sala de aula com a montagem com solo desprotegido, posteriormente foi utilizado o arranjo experimental com solo coberto por vegetação. Pediu-se aos alunos que atentassem ao comportamento da água pluvial e suas feições resultantes. Ao término de cada uma das montagens foi coletada e armazenada a água de escoamento superficial através de um balde plástico.

No experimento com solo exposto observou-se que parte da água de chuva percolou nos horizontes do solo (infiltração), porém, a maior parte do líquido escoou através da superfície, por meio de fluxo confinado ou em corrente. Deste modo, verificou-se o surgimento de pequenos canais que, com o prosseguimento da chuva, aumentaram de tamanho, formando sulcos bem definidos, caracterizando assim a erosão linear.

Por sua vez, na montagem utilizando cobertura vegetal observou-se novamente que parte das águas pluviais se infiltrou no solo, enquanto a maior parte destas escoou pela superfície. Entretanto, desta vez,

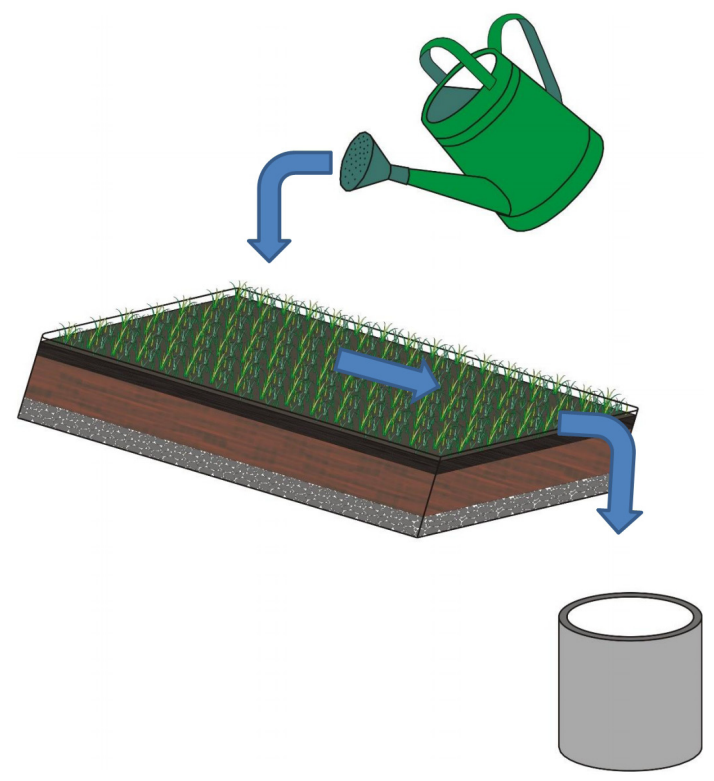

Figura 2. Montagem experimental esquematizada. As setas indicam a trajetória da água, inicialmente como simulação de chuva, posteriormente como escoamento superficial, a ser coletado no balde plástico. 
a água formou um lençol d'água, caracterizando um fluxo difuso ou desconfinado, que promoveu a remoção progressiva e uniforme da porção mais superficial do solo, caracterizando assim a erosão laminar ou em lençol.

Por fim, foi pedido para que os alunos correlacionassem as informações e observações da aula prática com situações vividas no seu cotidiano ou vistas no noticiário, compartilhando suas experiências pessoais na construção do conhecimento. Assim, foi suscitado um debate sobre a relação entre as ações antrópicas, processos erosivos e degradação do meio ambiente. A partir da discussão realizada e de suas próprias reflexões os alunos redigiram um texto sobre os impactos ambientais e socioeconômicos decorrentes dos processos erosivos desencadeados pela ação humana, e responderam um pequeno questionário de satisfação sobre as atividades interativas.

\section{Resultados obtidos}

No início da aula prática foi suscitado que os estudantes expressassem seus conhecimentos sobre solos, enfocando suas características, composição, funções e importância. Deste modo, o conceito de solo foi construído a partir das concepções e discussão de ideias dos próprios alunos, orientados e incentivados pelos pesquisadores, constituindo um processo indutivo de aprendizagem.

Em seguida foi realizado o experimento com o auxílio de alguns alunos voluntários. Após cada experimento ao se analisar a água de escoamento superficial coletada nos baldes, os estudantes verificaram que o líquido oriundo da montagem com solo exposto era muito mais turvo ("sujo") do que aquele obtido no modelo com solo vegetado, refletindo a maior quantidade de sedimentos carreados pela água em solo desnudo e desprotegido. Assim, foi mostrado que os processos e feições observados no primeiro modelo aplicado são condizentes com a erosão linear. Neste processo a água escoa com grande facilidade pelo solo exposto, retirando boa parte de seus constituintes que são transportados para outros lugares.

$\mathrm{Na}$ segunda montagem estudada (com vegetação), os alunos puderam observar que a água de escoamento superficial provoca o surgimento de canais levemente definidos. Deste modo, tem-se o desgaste uniforme e gradual do solo em toda a sua extensão, caracterizando a erosão laminar. Além disso, a menor turbidez da água de escoa- mento indica menor perda de partículas minerais e orgânicas constituintes do solo. Assim, chegou-se à conclusão que a presença de vegetação auxilia na preservação do solo, e que os processos erosivos, quando não controlados, podem levar a severa perda de solo. Esta afirmação vai de encontro com Bertoni (1990), segundo o qual "a vegetação promove maior infiltração das águas da chuva e protege a camada superficial do solo da erosão associada ao escoamento concentrado". Estimativas de taxa de erosão feitas por Sánchez (2013) mostram que a substituição da mata nativa por pastagem implica em um aumento de até 10 vezes na intensidade da erosão. No caso do plantio de culturas, como o arroz e a cana-de-açúcar, o aumento fica entre 30 e 1.600 vezes (Tabela 1). Esta tabela foi apresentada aos alunos como forma de incrementar a discussão.

Um grande debate sobre a erosão foi protagonizado pelos alunos e guiado pelos pesquisadores. A discussão foi pautada na tentativa de criar nos alunos a consciência do papel do homem como agente modificador da paisagem, e enfatizar que a atividade humana provoca impactos ambientais em escala local e global. Nesta abordagem geoética e de sustentabilidade foram discutidos temas como:

$\checkmark$ perda de áreas cultiváveis, diminuindo e encarecendo a produção de alimentos, que acarretam em graves problemas econômicos e sociais;

$\checkmark$ assoreamento de córregos, que impactam na fauna e flora, bem como na própria população;

$\checkmark$ deterioração de zonas de recarga de aquíferos, especialmente os aquíferos livres e rasos, afetando a captação e a qualidade de águas subterrâneas;

$\checkmark$ uso e ocupação indevidos do solo, que podem iniciar e/ou acelerar os processos erosivos.

Neste último tópico foi citado pelos próprios alunos um exemplo prático de seu cotidiano: um córrego que passa a pouco mais de 300 metros da escola. Neste local, há um processo acelerado de erosão às margens da drenagem, em decorrência da retirada indevida da mata ciliar e da intensa impermeabilização das vertentes, produto da rápida e desordenada expansão urbana. Contribui para este cenário o substrato rochoso em que o córrego está assentado. Tratam-se dos siltitos argilosos da Formação Corumbataí, que são empastilhados e facilmente escaváveis. Assim, foi possível reforçar os impactos ambientais decorrentes da urbanização não planejada. 
Tabela 1. Estimativas de taxas de erosão, segundo diferentes categorias de uso do solo.

\begin{tabular}{l|l|c}
\hline TIPO DE USO (LOCAL) & CONTEXTO GEOMORFOLÓGICO & $\begin{array}{l}\text { PERDA DE SOLO } \\
\text { (t./ha/ano) }\end{array}$ \\
\hline $\begin{array}{l}\text { Floresta Amazônica primária. (Rorai- } \\
\text { ma) }\end{array}$ & $\begin{array}{l}\text { Vertente com declividade de 20\% latossolo } \\
\text { vermelho-amarelo. }\end{array}$ & 150 \\
\hline $\begin{array}{l}\text { Pastagem de Brachiaria em antiga área } \\
\text { de floresta primária. (Roraima) }\end{array}$ & $\begin{array}{l}\text { Vertente com declividade de 20\% latossolo } \\
\text { vermelho-amarelo. }\end{array}$ & 1.128 \\
\hline $\begin{array}{l}\text { Floresta Amazônica primária. (Ron- } \\
\text { dônia) }\end{array}$ & & 330 \\
\hline $\begin{array}{l}\text { Pastagem, (Rondônia). } \\
\text { Mata. (Goiânia) }\end{array}$ & $\begin{array}{l}\text { Vertente com declividade de 16\% latossolo } \\
\text { vermelho-amarelo. }\end{array}$ & 3.556 \\
\hline $\begin{array}{l}\text { Vertente com declividade de 14\% latossolo } \\
\text { vermelho-amarelo. }\end{array}$ & $\begin{array}{l}\text { Vertente com declividade de 11\% latossolo } \\
\text { vermelho-amarelo. }\end{array}$ \\
\hline $\begin{array}{l}\text { Floresta nativa, reflorestamento e pas- } \\
\text { tagens. (Piracicaba) }\end{array}$ & $\begin{array}{l}\text { Vertentes com declividade de 0,5\% a 1\% neos- } \\
\text { solos litólicos. } \\
\text { Cultivo de cana-de-açúcar. (Piracicaba) } \\
\text { sertentes com declividade de 0,5\% a 1\% neos- }\end{array}$ & 230 \\
\hline
\end{tabular}

A aula prática foi desenvolvida e aplicada utilizando atividades interativas e multissensoriais, procurando fomentar a participação ativa e o compartilhamento de experiências dos próprios alunos. Assim, buscou-se prender a atenção do estudante, suscitar dúvidas, questionamentos, bem como aguçar sua curiosidade e promover um amplo debate de ideias, enfatizando as relações entre a humanidade e a geosfera e a questão da sustentabilidade. Deste modo, foi possível exercitar o senso crítico e ampliar o ponto de vista dos discentes (Fig. 3).

No decorrer das atividades interativas os alunos foram participativos e proativos, auxiliando na execução dos experimentos, como molhar as montagens com regador e coletar a água de escoamento superficial com o balde (Figura 4). Além disso, a maior parte dos estudantes participou das discussões, compartilhando suas experiências e conhecimentos. Tais atitudes demonstraram o interesse despertado pela atividade prática, concordando com as observações feitas por Pavani (1997).

Por fim, foi pedido para que os alunos escrevessem um texto com suas reflexões sobre os processos erosivos decorren-

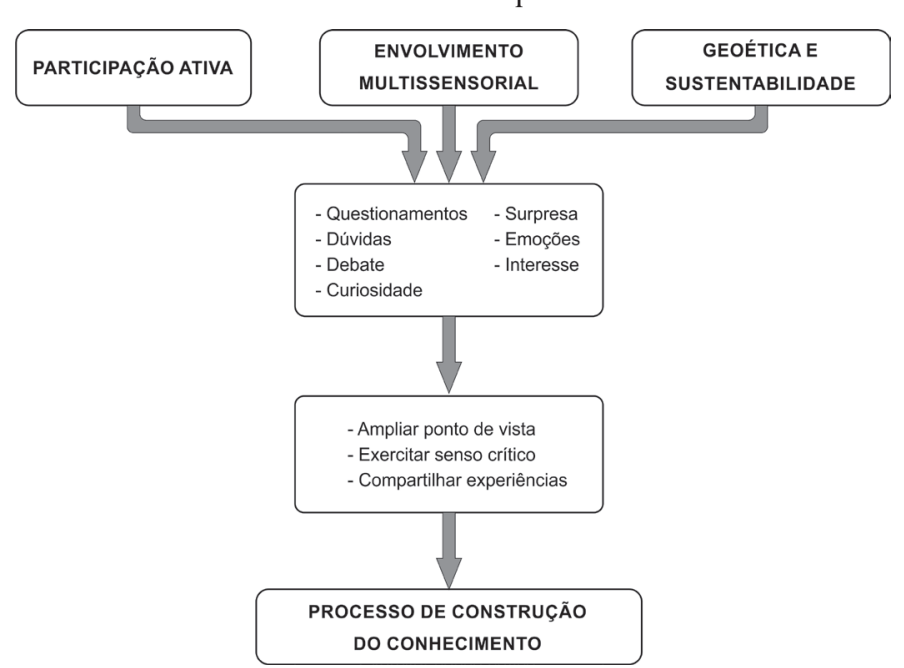

Figura 3. Fluxograma ilustrando a contribuição das atividades interativas no processo de construção do conhecimento. Modificado de Magagna et al. (2012). tes da ação do homem e os impactos ambientais e socioeconômicos decorrentes. Além disso, eles preencheram um questionário de satisfação sobre o experimento e a aula prática. Tal material foi analisado qualitativamente e mostrou que, de modo geral, os estudantes tiveram um desempenho satisfatório nas respostas e que a maioria gostou das atividades interativas, expressando interesse em ter esse tipo de aula com maior frequência.

ISSN 1679-2300 


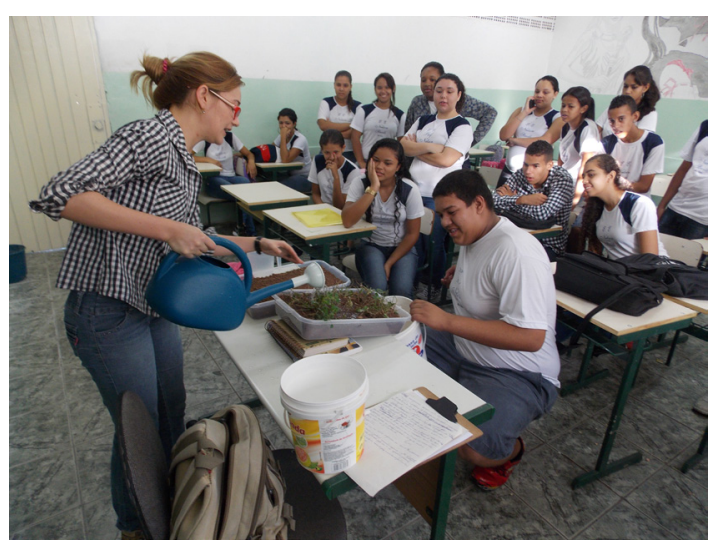

Figura 4. Aplicação do experimento em turma do $2^{\circ}$ ano do ensino médio da Escola Estadual Nelson Stroilli, Rio Claro/SP.

\section{Considerações finais}

Conseguiu-se realizar com sucesso a construção e adaptação do experimento portátil de erosão do solo. A referida montagem experimental é de baixo custo, podendo inclusive fazer uso de materiais recicláveis ou reutilizáveis.

A adoção da aula prática com o uso de experimentos facilitou a visualização dos processos erosivos e, consequentemente, a sua compreensão. Assim, a aula se tornou mais atraente e interessante, prendendo a atenção dos estudantes.

A abordagem didática adotada envolvendo atividades interativas e multissensoriais, juntamente com o constante estímulo para a participação ativa e o compartilhamento de experiências dos próprios alunos também foi essencial para o sucesso da aula. Esta prática suscitou dúvidas, questionamentos, reflexões e um amplo debate de ideias. Tal processo foi conduzido pelos pesquisadores, enfatizando as relações entre a humanidade e a geosfera, bem como a questão do desenvolvimento sustentável. Assim, foi possível exercitar o senso crítico e ampliar o ponto de vista dos discentes. Logo, esta abordagem possibilitou uma maior interação professor-aluno, tornando a aula mais didática e dinâmica. Além disso, houve um efetivo ganho de aprendizado, como indicado na avaliação qualitativa dos questionários respondidos pelos alunos.

Portanto, este tipo de experimentação valoriza o conhecimento do aluno e o aproxima do conhecimento científico, aguçando sua curiosidade. Isto faz com que ele se torne (e se veja como) agente ativo do processo de aprendizagem, contribuindo para a reflexão crítica e compreensão das problemáticas contemporâneas.

\section{Agradecimentos}

Os autores agradecem à Prof. ${ }^{a}$ Dr. ${ }^{a}$ Rosely Imbernon e ao relator anônimo pelas considerações e sugestões que contribuíram para o aprimoramento deste artigo. A primeira autora agradece ainda à Pró-Reitoria de Extensão Universitária (Proex) da UNESP pela concessão da Bolsa de Apoio Acadêmico e de Extensão (BAAE I).

\section{Referências}

Bertoni J. 1990. Conservação do solo. São Paulo: Ícone. $360 \mathrm{p}$.

Brady N.C., Weil R.R. 2013. Elementos da natureza e propriedades dos solos. Porto Alegre: Bookman, $3^{\mathrm{a}}$ ed. 685 p.

Brasil. Ministério da Educação e Cultura. Secretaria de Educação Fundamental. 2001a. Parâmetros Curriculares Nacionais: introdução aos parâmetros curriculares nacionais. 3. ed. Brasília, v.1. 126p.

Brasil. Ministério da Educação e Cultura. Secretaria da Educação Fundamental. 2001b. Parâmetros Curriculares Nacionais: Ciências Naturais. 3. ed. Brasília, v.4. 136p.

Capeche C.L. 2009. Confecção de um simulador de erosão portátil para fins de educação ambiental. Rio de Janeiro: Embrapa Solos. 31 p. (Docs. 116).

Descartes R. 1996. Discurso do método. São Paulo: Martins Fontes. 102p.

Departamento de Solos e Engenharia Agrícola - UFPR. Programa Solo na escola. Experimentoteca de solos. s.d. URL: < http://www.escola.agrarias.ufpr.br/ index_arquivos/experimentoteca.htm $>$. Acesso 05.01.2015.

EACH-USP, UNIFESP. Ciência à Mão. s.d. URL: < http://www.cienciamao.usp.br/tudo/indice.php $>$. Acesso 05.01.2015.

ESALQ. Solo na Escola. ESALQ. s.d. URL: < http:// solonaescola.blogspot.com.br/p/experimentos. html>. Acesso 05.01.2015.

Falconi S. 2004. Produção de material didático para o ensino de solos. Rio Claro: Inst. Geoc. Ciênc. Exatas, Univ. Est. Paul. (Dissert. Mestr. Geografia).

Falconi S., Nascimento N.R. 2005. Produção de material didático para o ensino de solos. In: Mendes A.A., Lombardo M.A. eds. 2005. Paisagens Geográficas e Desenvolvimento Territorial. Rio Claro: AGETEO/UNESP. p. 289-301.

Falconi S., Athayde B.A.C.C. 2009. O projeto $A B C$ da educação científica - mão na massa: aproximações e distanciamentos com o cotidiano escolar. In: Encontro Nacional de Prática de Ensino em Geografia, n.10, Porto Alegre. URL: < http://www.agb.org.br/XENPEG/ artigos/Poster $>$. Acesso 05.01.2015.

Geologist's Association. Earth Learning Idea. 2007. URL: 
$<$ http://www.earthlearningidea.com $>$. Acesso 03.05.2015.

Imbernon R.A.L., Toledo M.C.M., Honório K.M., Tufaile A.P.B., Vargas R.R.S., Campana P.T., Falconi S. 2009. Experimentação e interatividade (hands-on) no ensino de ciências: a prática na praxis pedagógica. Experiências em Ensino de Ciências, 4(1): 79-89. Maio 2009

Laboratório de Recursos Didáticos em Geociências UNICAMP. Geoideias. s.d. URL: < http://www. ige.unicamp.br/lrdg/geoideias.html>. Acesso 03.05.2015.

Lepsch I.F. 2010. Formação e conservação dos solos. São Paulo: Ofic. Textos, $2^{\mathrm{a}}$ ed. 216p.

Lima V.C. 2009 Contribuição do Projeto de Extensão Universitária Solo na Escola do Departamento de Solos da Universidade Federal do Paraná para o ensino de solos. Synergismus scyentifica, 4(1): 85-87. Anais da I Reunião Paranaense de Ciência do Solo. Núcleo Regional Paraná da Sociedade Brasileira de Ciência do Solo. Pato Branco: UTFPR.

Magagna A., Ferrero E., Giannatempo C. 2012 Interactive activities to stimulate debate and critical thinking about issues related to Earth sciences and sustainable development. Annals of Geophysics,
55(3): 453-460. Geoethics and geological culture. Reflections from the Geoitalia Conference 2011.

Miranda G.A., Matrangolo W.J.R., Moreira, J.A.A., Rezende, M.Q. 2010. Utilização de um simulador de erosão como ferramenta de educação ambiental. Sete Lagoas: Embrapa Milho e Sorgo. 38 p. (Docs. 116).

Pavani M.R. 1997. A Geografia e o trabalho em sala de aula: o real e o necessário. Rio Claro: Inst. Geoc. Ciênc. Exatas, Univ. Est. Paul. (Dissert. Mestr. Geografia).

Sánchez L.E. 2013. Avaliação de impacto ambiental: conceitos e métodos. São Paulo: Ofic. Textos, $2^{\mathrm{a}}$ ed. $583 \mathrm{p}$.

Vale J.M.F. 1998. Educação Científica e Sociedade. Módulo 3: O Conhecimento em cada área: significado, procedimentos e reorientação do cotidiano: área de Ciências. Bauru: Unesp, SEE, Delegacia de Ensino. Bauru, 1998. Proj. Educ. Contin. 19961998.

Vasconcelos C.M., Almeida A. 2014. Sustentabilidade e questões de (Geo)ética. Revista de Ciência Elementar, 2(3): 86-89.

Vasconcelos C.M., Imbernon R.A.L. 2015. Geoética no caminho da educação para o desenvolvimento sustentável. In: $6^{\circ}$ EnsinoGEO. Campos do Jordão, Out. 2015. Anais... SBG - Núcleo São Paulo.

Resumo: A geoética é um campo interdisciplinar da ética aplicada às geociências, invocando uma atitude ética e responsável da humanidade para com a geosfera. Para isto, a formação de uma consciência ambiental e a difusão da educação ambiental são essenciais, especialmente nos jovens. Assim, a escola se torna o palco ideal para se discutir e desenvolver projetos de educação ambiental. No presente trabalho discute-se sobre a utilização da experimentação como ferramenta didática. Além disso, descreve- se a adaptação de um simulador portátil de erosão do solo, relatando os resultados obtidos da aplicação do experimento em uma aula prática em escola pública. A abordagem didática adotada foi a de estimular a participação ativa e 0 compartilhamento de experiências dos próprios alunos através de atividades interativas. Deste modo, buscou-se aprimorar a percepção, a capacidade analítica, bem como exercitar a reflexão e o senso crítico dos estudantes, desenvolvendo assim uma educação emancipatória. A avaliação preliminar e qualitativa das atividades mostrou um ganho efetivo de aprendizado. Assim, este trabalho contribuirá para a inclusão do ensino das Geociências nas Escolas.

Palavras-chave: Experimentação; Erosão do Solo; Geoética; Educação Ambiental. 